\title{
Are Off-Label Prescriptions of ACE Inhibitors a Promising Therapy for COVID-19?
}

\author{
Eugene J Koprowski* \\ Albany Medical College/Alden March Bioethics Institute Albany, USA
}

*Corresponding author: Eugene J Koprowski, Albany Medical College/Alden March Bioethics Institute Albany, 409 North McKinley Avenue, Champaign, Illinois 61821 USA.

To Cite This Article: Eugene J Koprowski, Are Off-Label Prescriptions of ACE Inhibitors a Promising Therapy for COVID-19?. 2020 - 9(6). AJBSR. MS.ID.001448. DOI: 10.34297/AJBSR.2020.09.001448.

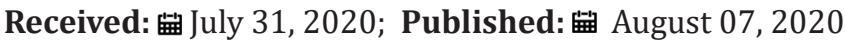

\section{Opinion}

New research published in a leading academic journal shows promise for potentially treating the SARS/COVID-19 virus by targeting angiotensin converting enzymes (ACE). Why don't we speed up the process of therapeutic discovery by exploring whether off-label prescriptions of ACE inhibitors already approved by regulators work in clinic in treating COVID?

COVID kills an estimated $13.4 \%$ of patients 80 and older, contrasted with $1.25 \%$ of those in their 50 s and $0.3 \%$ of those in their $40 \mathrm{~s}$, and is a serious public health threat. Nature Magazine is reporting that COVID-19 binds to the body's angiotensin-converting enzyme, a receptor on human cells [1].

The researchers note that a protein from the virus binds to the ACE2 receptor at least ten times as tightly as the protein in the SARS virus. A team led by David Vessler, a virologist at the University of Washington, indicates that the receptor, ACE 2, is a potential target for therapies to combat COVID-19. "For example, a drug that blocks the receptor might make it harder for coronavirus to enter cells," Nature Magazine reports [2].

This is excellent news. The U.S. Food and Drug Administration and other regulators across the planet have already approved ACE inhibitors, like lisonopril, moexipril, and ramipril for treatment of hypertension. My personal view -- building upon the work of Vessler, et al, -- is that the FDA and the makers of these drugs, and drugs like them, should immediately consider "off-label" use of the drugs to treat those infected with COVID [3]. Off-label therapies are use of medications that are approved by government regulators for purposes other than their initial use.

The therapies are a form of translational medicine in the clinic. Since many elderly who have dementia already are co-morbid with hypertension and may already be taking the ACE-inhibiting drugs, researchers can also immediately examine whether those taking the drugs are immune to COVID-19. Compared to the rest of the population, the elderly has an elevated risk of contracting the new virus, according to a report by N. Furguson of Imperial College, London, published in Lancet Infectious Diseases. Many elderly already take ACE inhibitors for hypertension.

Medicine in my view should move as quickly as possible to investigate the off-label use of approved drugs to target the cellular receptors that can block the spread of this pandemic among the elderly and other patient cohorts.

\section{Reference}

1. Mallapaty S (2020) Why does the coronavirus spread so easily between people? Researchers have identified microscopic features that could make the pathogen more infectious than the SARS virus - and serve as drug targets. Nature.

2. Begley S (2020) What explains Covid 19's lethality for the elderly.

3. WebMD, Types of ACE Inhibitors. 